\title{
BIOLOGIA FLORAL E HETEROSTILIA EM VISMIA GUIANENSIS (AUBL.) CHOISY (CLUSIACEAE)
}

\author{
Mary Janice Lima dos Santos ${ }^{1}$ \\ Isabel Cristina Machado ${ }^{1}$
}

\section{Recebido em 28/01/1999. Aceito em 01/07/1999}

RESUMO - (Biologia floral e heterostilia em Vismia guianensis (Aubl.) Choisy (Clusiaceae). Os estudos da biologia floral e reprodutiva e a caracterização da heterostilia em Vismia guianensis realizaram-se na Reserva Ecológica de Dois Irmãos, Recife, PE, entre novembro/1997 e fevereiro/ 1998. V. guianensis é arbustiva, apresenta flores heterostílicas, distílicas, dispostas em panículas terminais. A antese é diurna e as flores têm duração de um dia. $\mathrm{O}$ volume de néctar das flores foi ca. $2,0 \mu \mathrm{l}$ e a concentração de açúcares variou entre $46 \%$ e $68 \%$ nas duas formas florais. A viabilidade polínica foi aproximadamente de $93 \%$ nos dois tipos de flores. Com relação ao sistema reprodutivo, os testes de polinização controlada demonstraram que $V$. guianensis é autoincompatível, só produzindo frutos $(55-65 \%)$ a partir da polinização interformas. Foram observadas visitas de Polybia sp. (Vespidae) e de diferentes espécies de abelhas, das quais Hylaeus sp. (Colletidae) e Augochloropsis sp. (Halictidae) foram as mais frequentes, sendo considerados, juntamente com Polybia sp., como os polinizadores efetivos. Devido ao sistema de reprodução do tipo xenogâmico, associado à heterostilia, o papel dos polinizadores é de fundamental importância para promover a reprodução sexuada da espécie.

Palavras-chave - Vismia, Clusiaceae, heterostilia, melitofilia, pólen, biologia floral

ABSTRACT - (Floral biology and heterostyly in Vismia guianensis (Aubl.) Choisy (Clusiaceae). The floral and reproductive biology of Vismia guianensis was studied in the Ecological Reserve of "Dois Irmãos", in Recife (PE), northeastern Brazil, from November/1997 to February/1998. V. guianensis is a shrubby species, wherein the flowers, heterostyled of the dimorphic type, are arranged in terminal panicles. The anthesis is diurnal and the flowers last for one day. Nectar volume was about $2,0 \mu \mathrm{l}$, the sugar concentration varying from $46 \%$ to $68 \%$ in the two types of flowers. Pollen viability was ca. $93 \%$ for both long and short styled-flowers. V. guianensis is a self-incompatible species. Only the intermorph pollinations produced fruits (55-65\%). Visits by Polybia sp. (Vespidae) and several species of bees were observed to flowers of V. guianensis. Hylaeus sp. (Colletidae), and Augochloropsis sp. (Halictidae) were the most frequent visitors, and were considered, together with Polybia sp., the effective pollinators. Due to the xenogamic reproductive system associated to the heterostylous mechanism, the pollinators have a fundamental role in promoting sexual reproduction in this plant species.

Key words - Vismia, Clusiaceae, heterostyly, melittophily, pollen, floral biology

1 Departamento de Botânica, CCB, Universidade Federal de Pernambuco, CEP 50372-970, Recife, PE, Brasil. e-mail: mary@npd.ufpe.br; icmachado@npd.ufpe.br 


\section{Introdução}

A família Clusiaceae Lindley possui 47 gêneros e 1.350 espécies, distribuídos principalmente nos trópicos (Mabberley 1993). Em Pernambuco está representada por sete gêneros nativos (Andrade-Lima 1950; 1960; Mariz \& Leal 1972; Mariz 1974a; 1974b) e dois exóticos, totalizando cerca de 25 espécies (Mariz 1989). O gênero Vismia Vand. é constituído por 35 espécies tropicais (Mabberley 1993) ocorrendo em vegetações típicas de capoeira e borda de mata, sendo V. guianensis (Aubl.) Choisy espécie arbustiva das mais comuns (van den Berg 1971).

Os estudos referentes à biologia floral em Clusiaceae concentram-se, em sua maioria, no gênero Clusia, sendo enfatizada principalmente a produção de resina como recompensa floral (Correia et al. 1993; Bittrich \& Amaral 1997; Lopes \& Machado 1998). A ocorrência de heterostilia na referida família foi investigada apenas nos gêneros Hypericum e Cratoxylum (Ornduff 1975; 1979; Lewis 1982), embora tenha sido mencionada para Vismia e Eliaeo por Ornduff (1975). Em relação ao gênero Vismia, tanto as informações sobre a biologia floral e reprodutiva, quanto a caracterização da heterostilia são escassas, havendo algumas informações nos trabalhos de Ganders (1979), Sobrevila \& Arroyo (1981) e Barrett \& Richards (1990).

Neste trabalho foram estudados aspectos da biologia floral e reprodutiva de $V$. guianensis, com ênfase na ocorrência de heterostilia, contribuindo para o conhecimento da dinâmica reprodutiva desta espécie.

\section{Material e métodos}

Os estudos de campo foram desenvolvidos na Reserva Ecológica de Dois Irmãos

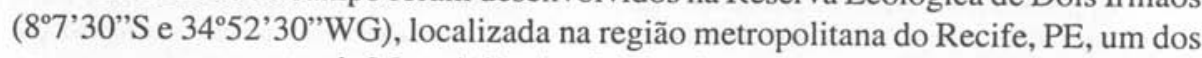
poucos remanescentes de Mata Atlântica do Estado, entre novembro/1997 e fevereiro/ 1998. A Reserva possui aproximadamente 370 ha e está distribuída em área de relevo levemente ondulado, com altitude de 30 a $80 \mathrm{~m}$, onde as precipitações pluviométricas atingem anualmente cerca de $2.000 \mathrm{~mm}$. A temperatura do ar tem como valores mínimos $24^{\circ} \mathrm{C}$ nos meses de junho a agosto, e valores máximos de $27^{\circ} \mathrm{C}$ de dezembro a março (Machdo et al. 1998).

Todas as observações e experimentos de campo foram realizados utilizando-se indivíduos com flores brevistilas e longistilas. Foram marcados 15 indivíduos, 10 brevistilos e 5 longistilos, e feitas observações sobre a morfologia, tamanho, cor e duração da flor, horário e sequiência de antese, número de botões por inflorescência, localização e tipo de recompensa floral.

Os comprimentos dos estames e estiletes foram medidos com o auxílio de régua milimetrada, sendo posteriormente aplicado o teste t (Zar 1996) para verificar se a distância entre estames e estigmas, nas duas formas florais diferia significativamente.

A receptividade dos estigmas foi testada com $\mathrm{H}_{2} \mathrm{O}_{2}$ (Zeisler 1938; Galen \& Plowright 1987) e observada com lupa de campo.

A viabilidade polínica foi verificada utilizando-se a técnica de coloração do citoplasma com carmim acético $1,2 \%$ (Radford et al. 1974). Foram utilizados cinco botões em fase de pré-antese de cada tipo floral, provenientes de quatro indivíduos. Os 
grãos de pólen foram retirados de cada antera, sob estereomicroscópio e espalhados em lâmina histológica contendo uma gota do referido corante. Em microscópio óptico, foram contados 300 grãos de pólen distribuídos ao acaso em cada lâmina, separandose os inviáveis dos viáveis.

A contagem do número de grãos de pólen por antera foi realizada utilizando-se câmara de Neubauer (Maêda 1985). Foram utilizados vinte botões em fase de préantese, coletados de indivíduos diferentes, sendo dez brevistilos e dez longistilos. De cada botão isolou-se uma antera, que foi fixada em ácido lático e glicerina (3:1), segundo Lloyd (1972). A razão pólen:óvulo foi calculada dividindo-se o número de grãos de pólen pelo número de óvulos em cada flor (Cruden 1977).

O estudo da morfologia polínica foi realizado utilizando-se a técnica da acetólise (Erdtman 1966) em anteras de dez flores, separadas e fixadas em ácido acético glacial de acordo com o tipo morfológico (flores brevistilas e longistilas). Foram preparadas 10 lâminas histológicas de cada tipo floral, e, com auxílio de ocular micrométrica acoplada a microscópio óptico, foram feitas medidas dos diâmetros equatorial e polar em vista equatorial, de 25 grãos de pólen distribuídos ao acaso nas diversas lâminas. As medidas realizaram-se no prazo máximo de oito dias, após a montagem das lâminas, sendo feitas análises estatísticas, incluindo cálculos da média aritmética (x), desvio padrão da média ( $\mathrm{Sx}$ ), desvio padrão da amostra $(\mathrm{S})$ e do coeficiente de variabilidade (V).

A concentração e o volume do néctar foram medidos, respectivamente, com auxílio de refratômetro de bolso (0-32\% e 28-62\%) e seringas micrométricas. Flores brevistilas e flores longistilas em pré-antese foram ensacadas, sendo as medidas efetuadas no campo, no dia seguinte. As primeiras medidas foram efetuadas no início da antese, por volta das $7: 00 \mathrm{~h}$, sendo estas repetidas a cada $2 \mathrm{~h}$, finalizando às $12: 00 \mathrm{~h}$. Para cada horário efetuaram-se 10 repetições.

Foram feitos desenhos detalhados em câmara-clara acoplada a estereomicroscópio de botões e flores fixados em etanol $70 \%$.

A fenologia da floração e da frutificação foi acompanhada semanalmente nos 15 indivíduos marcados. Foram utilizadas fichas de campo para registrar a presença ou ausência de botões, flores e frutos, seguindo as indicações de Morellato et al. (1990). O padrão de floração da espécie foi determinado a partir da classificação de Newstron et al. (1994).

Foram realizados, no campo, testes para verificação do sistema reprodutivo nas duas formas florais, segundo metodologia adaptada de Radford et al. (1974). Os tratamentos incluíram verificação da ocorrência de apomixia, autopolinização espontânea e manual, polinização cruzada, além da formação de frutos em condições naturais. Os cruzamentos foram realizados entre indivíduos do mesmo tipo floral e entre indivíduos de formas florais diferentes (brevistilos e longistilos). As flores foram emasculadas ainda na fase de botão com o auxílio de pinça fina. As flores utilizadas foram previamente encobertas com sacos de papel semi-permeável devidamente etiquetados, os quais só foram retirados após o murchamento da corola.

Foram realizadas observações no campo sobre o tipo, freqüência, horário e comportamento dos animais visitantes às flores, o recurso floral procurado e o resultado 
da visita (polinização ou pilhagem). As visitas foram documentadas com máquina fotográfica para auxiliar a descrição do comportamento. Alguns insetos visitantes foram capturados com rede entomológica e mantidos a seco para identificação, sendo posteriormente depositados na coleção do Laboratório de Biologia Floral e Reprodutiva, do Departamento de Botânica da UPPE. Foram analisados os atributos morfológicos dos animais, bem como os locais de deposição de pólen e contato com o estigma.

Foram herborizados ramos florais e frutíferos de indivíduos brevistilos e longistilos, de acordo com as normas usuais, sendo depositados como espécimestestemunho no Herbário do Departamento de Botânica da Universidade Federal de Pernambuco (UFP 21733, 21734).

\section{Resultados}

V. guianensis é uma espécie arbustiva, distribuída na borda da mata, podendo atingir de 2 a $5 \mathrm{~m}$ alt. A floração estendeu-se de novembro a março, prolongando-se até maio; em alguns indivíduos, o pico de floração ocorreu entre dezembro e janeiro.

A análise morfológica das flores indicou a presença de dois tipos florais, brevistilos e longistilos (Fig. 1), em indivíduos diferentes, o que caracteriza heterostilia do tipo distílica. Na Reserva Ecológica de Dois Irmãos a proporção de indivíduos com flores brevistilas e longistilas foi de 2:1.
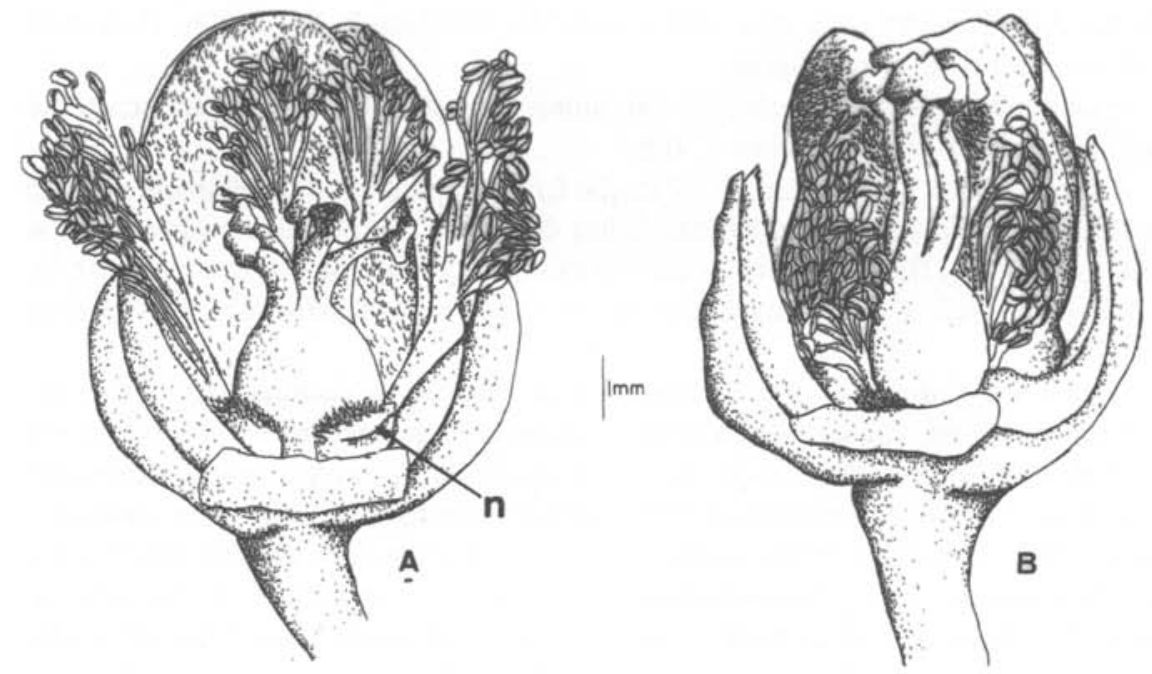

Figura 1. Esquema de flores em antese de Vismia guianensis. A-Flor brevistila. B-Flor longistila. $(\mathrm{n}=$ nectário $)$ 
As duas formas florais são actinomorfas, hemafroditas e pentâmeras. O cálice é dialissépalo, coriáceo, externamente ferrugíneo e esverdeado na face interna. A corola é dialipétala, formando um tubo com o comprimento médio de $0,7 \mathrm{~cm}$ e diâmetro médio de $0,4 \mathrm{~cm}$. As pétalas são membranáceas, coloração amarelo-esverdeada, com inúmeros pêlos distribuídos por toda a face interna. As flores estão reunidas em panículas terminais, contendo $20-60$ botões, abrindo-se geralmente 2-6 flores por dia.

$\mathrm{O}$ androceu é formado por cinco fascículos de estames com 30-50 elementos por fascículo. O comprimento dos estames difere nas duas formas florais, sendo mais longo nas flores brevistilas e mais curto nas longistilas. As anteras possuem deiscência longitudinal.

A média dos comprimentos dos estames e dos estiletes nas flores brevistilas foi de 0,68 e $0,41 \mathrm{~mm}$, respectivamente, enquanto que nas longistilas foi, respectivamente, de 0,40 e $0,69 \mathrm{~mm}$ (Fig. 2). Não foi verificada diferença significativa em relação às distâncias entre os estames das flores brevistilas e os estiletes das flores longistilas, bem como entre estames das flores longistilas e os estiletes das flores brevistilas $(t=$ 1,068; G.L. 18; P> 0,05).

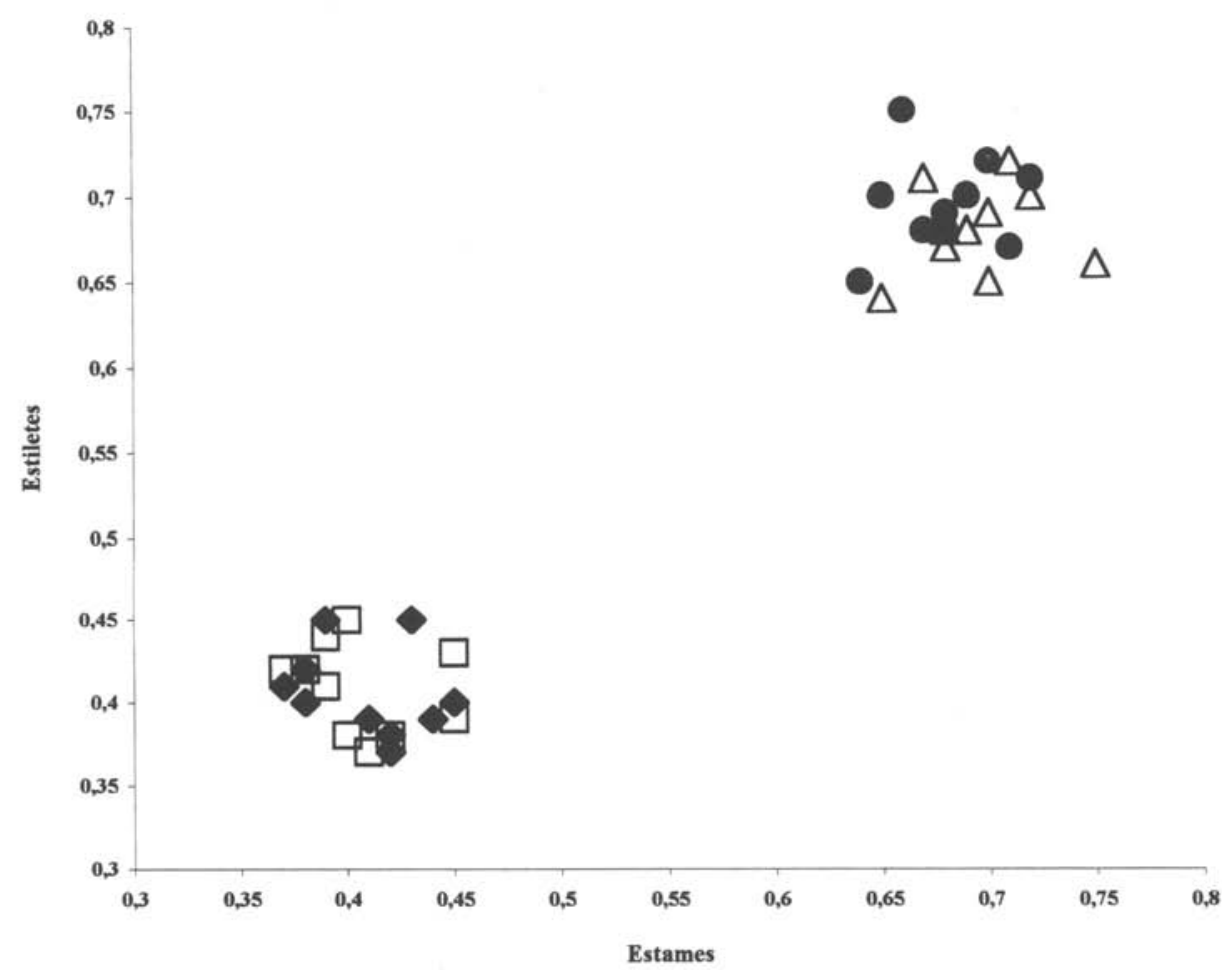

Figura 2. Relação entre o comprimento dos estames e estiletes das duas formas florais de Vismia guianensis. ( - Estilete da flor brevistila; $\square$ - Estame da flor longistila; $\Delta$ - Estilete da flor longistila; - Estame da flor brevistila.) 
O gineceu apresenta ovário súpero, pentacarpelar e pentalocular, com cerca de 25 óvulos por lóculo. Possui cinco estiletes terminais, com estigmas amplos apresentando papilas por toda a superfície, sendo que nas flores brevistilas os estigmas são ovalados, com papilas arredondadas, enquanto que nas flores longistilas os estigmas são circulares e alongados, com papilas maiores que as das flores brevistilas.

O néctar é produzido por estruturas glandulares (nectários), localizadas na base da corola, entre um grupo de estames e outro, onde fica acumulado. A concentração de açúcares no néctar variou entre 44 e $60 \%$ e o volume foi cerca de $2,0 \mu \mathrm{l}$ por flor.

O processo de antese inicia-se com o afastamento das pétalas por volta das 7:00h, estando as flores completamente abertas por volta das 10:00h. No final da tarde, ca. 16:00h, as flores fecham. A deiscência das anteras e a exposição dos grãos de pólen se dá logo após o início da antese. Durante o período de antese os estigmas apresentavamse esverdeados e receptivos, adquirindo coloração marrom após o murchamento da flor.

A viabilidade dos grãos de pólen, nas duas formas florais, foi elevada, sendo ainda maior nas flores brevistilas. Os resultados da razão pólen/óvulo encontram-se resumidos na Tab. 1. Observa-se que as flores brevistilas apresentam maior produção de grãos que as flores longistilas.

Tabela 1. Número de grãos de pólen por antera (G/A) e por flor (G/F), número de óvulos por flor (O/F), razão pólen óvulo (P/O) e viabilidade polínica (VP) de Vismia guianensis.

\begin{tabular}{lccccc}
\hline Vismia guianensis & $\mathrm{G} / \mathrm{A}$ & $\mathrm{G} / \mathrm{F}$ & $\mathrm{O} / \mathrm{F}$ & $\mathrm{P} / \mathrm{O}$ & VP \\
\hline Flores brevistilas & 24.000 & 5.760 .000 & 142 & 40.563 & $96 \%$ \\
Flores longistilas & 22.000 & 5.060 .000 & 136 & 37.205 & $90 \%$ \\
\hline $\mathrm{N}=10$ & & & & &
\end{tabular}

A análise da morfologia polínica demostrou que existe diferença entre o tamanho dos grãos, que são maiores nas flores brevistilas (Tab. 2). Nas duas formas florais os grãos são subtriangulares, tricolpados e com exina reticulada (Fig. 3).

Tabela 2. Medidas em vista equatorial dos diâmetros equatorial e polar dos grãos de pólen de Vismia guianensis.

\begin{tabular}{lcc}
\hline Dimensōes & flores brevistilas & flores longistilas \\
\hline Diâmetro polar $(\mathrm{P}):$ & & \\
\hline Faixa de variação $(\mu \mathrm{m})$ & $26-32$ & $18-22$ \\
$\mathrm{X} \pm \mathrm{Sx}(\mu \mathrm{m})$ & $30 \pm 0,19$ & $20,3 \pm 0,23$ \\
$\mathrm{~S}(\mu \mathrm{m})$ & 4,8 & 1,17 \\
$\mathrm{~V}(\%)$ & 16 & 5,74 \\
\hline Diâmetro equatorial $(\mathrm{E}):$ & & $16-20$ \\
\hline Faixa de variação(mm) & $18-21$ & $17,45 \pm 0,24$ \\
$\mathrm{X} \pm \mathrm{Sx}(\mu \mathrm{m})$ & $19,7 \pm 0,24$ & 1,21 \\
$\mathrm{~S}(\mu \mathrm{m})$ & 1,19 & 6,93 \\
$\mathrm{~V}(\%)$ & 3,9 & 1,16 \\
\hline P/E & 1,5 &
\end{tabular}

X-Média aritimética; Sx-Desvio padrão da média; S-Desvio padrão da amostra; V-Coeficiente de variabilidade. 

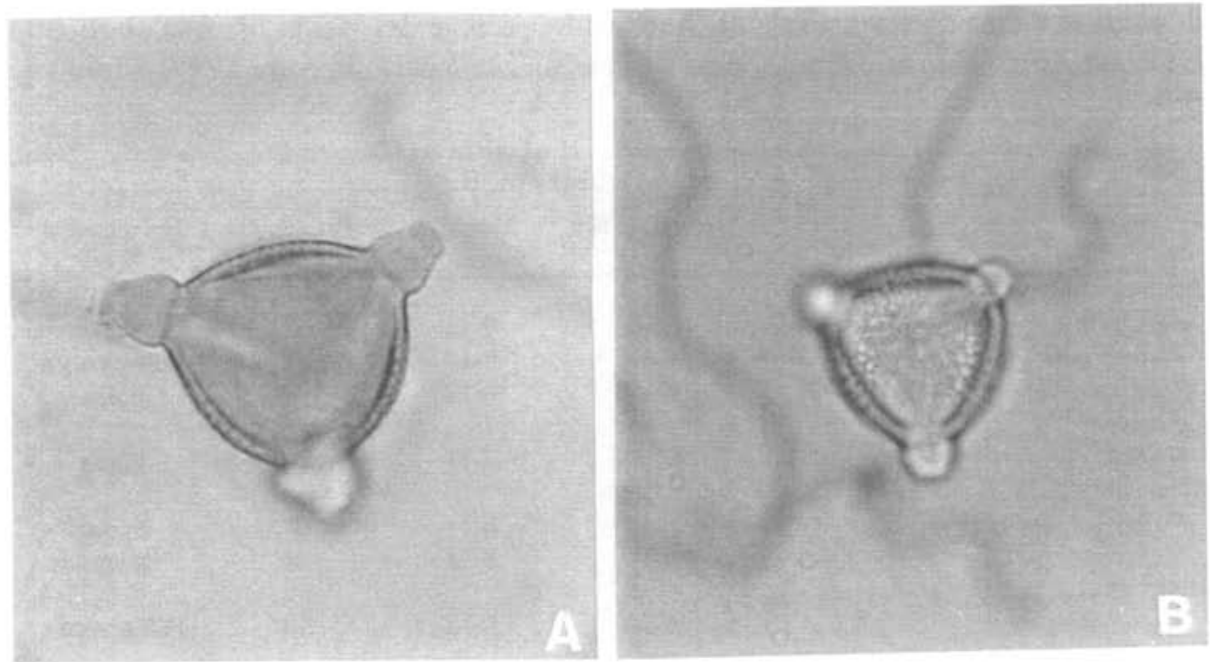

Figura 3. Pólen em vista polar de Vismia guianensis. A-pólen de flor brevistila. B-pólen de flor longistila

Os resultados referentes aos experimentos de polinização manual e ao número de frutos formados em condições naturais encontram-se na Tab. 3. Observa-se que $V$. guianensis é espécie autoincompatível e xenógama, uma vez que os testes de autopolinização, bem como os de polinização cruzada envolvendo flores do mesmo tipo morfológico, não resultaram na formação de frutos. Também não foram formados frutos apomíticos. A frutificação teve início em janeiro prolongando-se até junho. Em cada ramo podem-se encontrar 8 a 16 bagas.

Tabela 3. Resultado dos diferentes experimentos para verificação do sistema reprodutivo em Vismia guianensis.

\begin{tabular}{lccc}
\hline Tratamentos & $\begin{array}{c}\text { flores } \\
(\mathrm{n})\end{array}$ & $\begin{array}{c}\text { frutos } \\
(\mathrm{n})\end{array}$ & $\begin{array}{c}\text { sucesso } \\
(\%)\end{array}$ \\
\hline Apomixia & 20 & 0 & 0 \\
Autopolinização espontânea & 20 & 0 & 0 \\
Autopolinizção manual & 20 & 0 & 0 \\
$\begin{array}{l}\text { Geitonogamia } \\
\text { Polinização cruzada }\end{array}$ & 20 & 0 & 0 \\
$\quad$ fl. longistila* X fl. longistila** & 20 & 0 & 0 \\
fl. brevistila *X fl. brevistila** & 20 & 0 & 0 \\
fl. longistila *X fl. brevistila** & 20 & 11 & 55 \\
$\quad$ fl. brevistila *X fl. longistila** & 20 & 13 & 65 \\
Controle & & & \\
$\quad$ fl. brevistila & 20 & 7 & 17 \\
fl. longistila & 20 & 9 & 23 \\
\hline D. & & & \\
\hline
\end{tabular}

* Doador de pólen. ** Receptor de pólen.

Os visitantes às flores de $V$. guianensis apresentam comportamento semelhante tanto nas flores longistilas quanto nas brevistilas, tendo sido registradas sete espécies 
de abelhas e uma de vespa (Tab. 4). A maior frequência das visitas ocorreu entre 7:00 e 11:00h, tendo sido registradas visitas esporádicas no período entre 12:00 e 16:00 h.

\begin{tabular}{|c|c|c|c|c|}
\hline Visitantes & $\begin{array}{c}\text { Tempo na flor } \\
\text { (seg.) }\end{array}$ & $\begin{array}{c}\text { Horário } \\
\text { visitas (h) }\end{array}$ & $\begin{array}{l}\text { Freqüência } \\
\text { visitas }\end{array}$ & $\begin{array}{c}\text { Recompensa } \\
\text { floral }\end{array}$ \\
\hline \multicolumn{5}{|l|}{$\overline{\text { Apidae }}$} \\
\hline Apis mellifera L (1758) & $6-8$ & $9-11$ & $\mathrm{R}$ & Néctar \\
\hline Plebeia poecilochoroa Moure (1946) & $8-10$ & $8-12$ & MC & Pólen/néctar \\
\hline Trigona spinipes Fabricius (1793) & $30-40$ & $8-12$ & $\mathrm{C}$ & Pólen \\
\hline \multicolumn{5}{|l|}{ Colletidae } \\
\hline Hylaeus sp. & $40-60$ & $7-11$ & MC & Pólen \\
\hline \multicolumn{5}{|l|}{ Megachilinae } \\
\hline Megachile sp. 1 & $6-10$ & $8-11$ & $\mathbf{R}$ & Néctar \\
\hline Megachile sp. 2 & $6-10$ & $8-11$ & $\mathrm{R}$ & Néctar \\
\hline \multicolumn{5}{|l|}{ Halictidae } \\
\hline Augochloropsis sp. & $6-30$ & $8-12$ & MC & Pólen/néctar \\
\hline \multicolumn{5}{|l|}{ Vespidae } \\
\hline Polybia sp. & $20-30$ & $12-14$ & MC & Néctar \\
\hline
\end{tabular}

Hylaeus sp., Augochloropsis sp. e Polybia sp. foram os visitantes mais frequentes e eficientes às flores de V. guianensis (Fig. 4).

Hylaeus sp. visitava as flores logo no início da antese, quando as mesmas ainda estavam semi-abertas, aproximava-se pousando nas pétalas, penetrando em seguida na flor, onde realizava movimentos circulares em volta dos cinco grupos de estames, sempre manipulando as anteras com as mandíbulas e os dois primeiros pares de pernas para coleta de pólen, que aderia a parte interna do tórax e abdômen, sendo algumas vezes também encontrado nas pernas. Os estigmas eram contactados várias vezes, principalmente no momento de entrada e saída da abelha na flor.

Augochloropsis sp. iniciava as visitas quando a flor já estava completamente aberta, utilizando os grupos de estames e os pêlos das pétalas como superfície de pouso. Inseria apenas a cabeça e parte do tórax dentro da flor, vibrando as anteras, para coletar pólen. Após a coleta, limpava-se na própria flor ou nas folhas próximas, retornando em seguida para a mesma flor. Quando coletava néctar, a abelha penetrava totalmente na flor indo até a base da corola. Durante a coleta de pólen ou de néctar contactava os estames e estigmas muitas vezes, com várias partes do corpo.

Duas espécies de Megachile, assim como Apis mellifera, apresentaram comportamentos semelhantes. Ambas se aproximavam frontalmente das flores mais altas, penetravam na corola para coleta de néctar, contactando com a parte ventral do abdômen e do tórax nos estames e nos estigmas. As abelhas limpavam-se durante o vôo, transferindo o pólen para as corbículas, localizadas no terceiro par de pernas, visitando em média duas a três flores por inflorescência. Estas abelhas, no entanto, apresentavam baixa freqüência de visitas.

Trigona spinipes visitou esporadicamente os indivíduos de V. guianensis, com exceção de um único indivíduo, no qual foi a abelha mais freqüente. Esta comia partes 

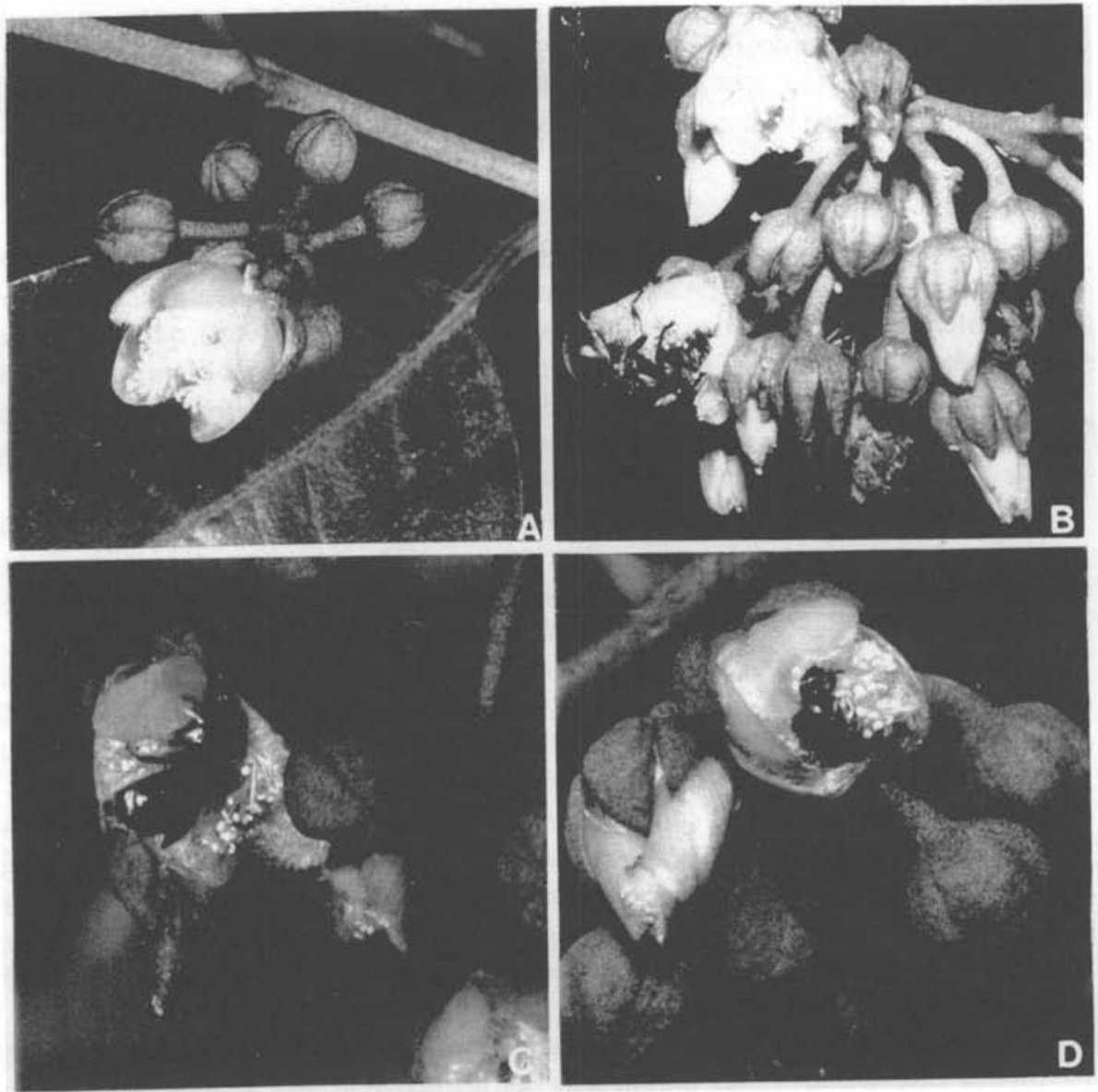

Figura 4. Flor e visitantes de Vismia guianensis. A. Flor brevistila. B. Polybia sp. coletando néctar. C. Augochloropsis sp. coletando néctar. D. Hylaeus sp. coletando pólen.

florais (pétalas e estames) e coletava pólen com as mandíbulas e o primeiro par de pernas.

Plebeia poecilochroa iniciava suas visitas logo no início da antese, coletando pólen e néctar. Para a coleta de pólen, pousava nas pétalas das flores utilizando as mandíbulas e o primeiro par de pernas, contactando esporadicamente os estigmas, devido ao seu pequeno tamanho. Quando coletava néctar, introduzia a probóscide entre as sépalas, sem tocar nas partes sexuais da flor.

Polybia sp. (Vespidae) iniciava suas visitas às flores de V. guianensis por volta das 12:00h, quando os outros visitantes praticamente não mais apareciam. Aproximavase da flor, pousava apoiando-se nas pétalas e nos pêlos existentes em seu interior, e, 
durante a coleta de néctar, tocava os estigmas e as anteras com a porção interna do tórax e algumas vezes do abdômen.

Durante todas as etapas do trabalho de campo observou-se a presença de formigas nas partes vegetativas e reprodutivas dos indivíduos de V. guianensis.

\section{Discussão}

Os dados de fenologia de floração, obtidos a partir das observações realizadas na Reserva Ecológica de Dois Irmãos, demonstram que a floração tem duração de quatro meses, diferindo dos resultados obtidos por Adolfo \& Andrade (1989), que observaram floração de oito meses em V. guianensis ocorrente em outra área de Mata Atlântica de Pernambuco. Em Dois Irmãos, o padrão de floração de V. guianensis é do tipo anual, apresentando apenas um ciclo de floração por ano, e intermediário por ter duração menor que cinco meses, segundo a classificação de Newstron et al. (1994).

V. guianensis apresenta vários atributos florais que a enquadram na síndrome de melitofilia (sensu Faegri \& Pijl 1979; Proctor et al. 1996), tais como: flor actinomorfa, coloração amarelada, antese diurna, corola formando tubo curto e largo, na base da qual se acumula pequena quantidade de néctar, com concentração elevada.

Abelhas e vespas necessitam de área de pouso nas flores durante as visitas (Faegri \& Pijl 1979), que em V. guianensis é representada pelas pétalas e pelos grupos de estames, sendo que nas flores longistilas as superfícies dos estigmas também desempenham esta função de plataforma de pouso.

Segundo definições encontradas em Percival (1965) e Endress (1994), $V$. guianensis é flor de néctar, embora ofereça pólen e néctar simultaneamente, como recompensa floral a seus visitantes. O néctar é considerado atrativo primário por Faegri \& Pijl (1979), servindo como alimento para muitos animais que visitam as flores repetidamente, promovendo desta maneira a polinização cruzada (Faegri \& Pijl 1979; Proctor et al. 1996).

A concentração do néctar é importante na relação planta-polinizador (Percival 1965). Por exemplo, as flores polinizadas por abelhas e vespas geralmente possuem néctar mais concentrado que as flores polinizadas por beija-flores e morcegos (Percival 1965). Isto foi verificado em V. guianensis, cuja concentração de néctar é semelhante à encontrada em outras flores melitófilas (Percival 1965; Baker 1975). A quantidade de néctar produzida por flor de $V$. guianensis é pequena $(2 \mu \mathrm{l})$, entretanto, devido à presença de várias flores abertas diariamente num mesmo indivíduo, a oferta torna-se maior. A baixa produção de néctar por flor induz o polinizador a realizar visitas a diversas flores, possibilitando a ocorrência de polinização cruzada e, conseqüentemente, o aumento do fluxo gênico.

A coloração das flores é considerada atributo secundário, atuando na atração dos polinizadores (Percival 1965; Faegri \& Pijl 1979). Os insetos apresentam maior sensibilidade nos comprimentos de onda correspondentes ao ultravioleta, azul e verdeamarelo (Proctor et al. 1996). A coloração amarelo-esverdeada da corola e ferrugínea do cálice das flores de $V$. guianensis é bastante atrativa aos visitantes, tornando as flores visíveis a longa distância. 
Nas flores de $V$. guianensis foi confirmada a ocorrência de heterostilia do tipo distílica. Segundo Lewis \& Jones (1992), geralmente há dominância de indivíduos brevistílicos sobre indivíduos longistílicos. A espécie estudada, em toda a mata, apresentou dominância da forma brevistílica. Entretanto, em Hypericum aegypticum Murr. (Ornduff 1979), os indivíduos longistílicos eram dominantes, e em Cratoxylon formosum (Lewis 1982) não foi observada dominância entre as duas formas florais. Portanto, ainda não se pode estabelecer um padrão para a família Clusiaceae, uma vez que os outros gêneros heterostílicos da família não foram estudados.

A heterostilia originou-se de maneira polifilética em várias famílias (Vuilleumier 1967; Ganders 1979). Existem várias características morfológicas e fisiológicas que diferem as formas florais heterostílicas, como diferenças no comprimento dos estames e estigmas, incompatibilidade interformas, diferenças na superfície estigmática e na morfologia polínica (Vuilleumier 1967; Ganders 1979). Outros polimorfismos florais, tais como forma e tamanho do tubo da corola e diferentes tamanhos entre flores brevistilas e longistilas foram referidos por Ganders (1979). Em V. guianensis vários destes polimorfismos puderam ser observados, sendo discutidos a seguir.

O fato de não haver diferença significativa entre as distâncias dos estames e estiletes das flores brevistilas com os estiletes e estames das flores longistilas, respectivamente, evidencia que a espécie se enquadra no modelo de hercogamia recíproca descrito por Hildebrand (1866 apud Vuilleumier 1967) e Ganders (1979).

As flores heterostílicas caracterizam-se por ter poucos estames, simetria actinomorfa e polinização entomófila (Proctor et al. 1996). Em V. guianensis, entretanto, os estames são numerosos e estão dispostos em feixes, característica pouco comum entre as espécies heterostílicas. Esta condição também foi observada em Hypericum aegypticum (Ornduff 1975) e Cratoxylon formosum (Lewis 1982).

Outro polimorfismo freqüente entre as espécies heterostílicas está relacionado com o tamanho e a forma das papilas estigmáticas. Vuilleumier (1967), Dulberger $(1975 ; 1992)$ e Richards (1986) afirmam que as papilas estigmáticas das flores longistilas seriam mais alongadas que nas flores brevistilas. Em V. guianensis este polimorfismo é bastante evidente, tendo as flores longistilas estigmas bem mais amplos e alongados que os das flores brevistilas.

A heterostilia normalmente está associada a dupla incompatibilidade (Barrett 1992), ou seja, não há formação de frutos a partir da autopolinização, nem entre cruzamentos com indivíduos da mesma forma floral. V. guianensis é autoincompatível, uma vez que, tanto nos testes de autopolinização, quanto nos de polinização cruzada entre flores do mesmo ou de indivíduos diferentes, porém da mesma forma floral, não houve formação de frutos. Obteve-se apenas sucesso nos cruzamentos inter-formas. Entretanto, Sobrevila \& Arroyo (1981) classificam Vismia bacifera (L.) Tr. \& Pl. como autocompatível, não se referindo a ocorrência de heterostilia na espécie.

A elevada razão pólen:óvulo (P/O) de $V$. guianensis é típica de xenogamia obrigatória, de acordo com a classificação de Cruden (1977), o que foi confirmado experimentalmente nos testes de cruzamento.

Segundo Dulberger (1992), nas flores heterostílicas há deposição assimétrica de grãos de pólen, nas quais o estigma das flores longistilas captam mais pólen que o das flores brevistilas. Este fato ocorre devido aos estiletes das flores longistilas serem mais 
longos, permitindo maior contato dos polinizadores com a superfície estigmática, que nesta forma floral é maior e mais alongada. V. guianensis apresentou maior produção de grãos de pólen nas flores brevistilas, o que, segundo Ganders (1979), neutralizaria o fluxo diferenciado de pólen entre as formas florais. A morfologia polínica distinta entre as duas formas florais é característica freqüentemente associada aos táxons heterostílicos (Darwin 1877 apud Vuilleumier 1967; Erdtman 1966; Vuilleumier 1967; Dulberger 1975, 1992; Richards 1986). Nos estudos de Dulberger (1975), em 55 espécies heterostílicas, 50 apresentavam heteromorfismo polínico. As análises morfológicas dos grãos de pólen de V. guianensis demonstraram que as flores longistilas possuem pólen significativamente menor que o das flores brevistilas. Esta diferença de tamanho deve estar relacionada à menor superfície estigmática observada nas flores brevistilas.

A maioria dos visitantes observados é capaz de polinizar as flores de $V$. guianensis. Entretanto, de acordo com a freqüência das visitas e o tipo de comportamento, Augochloropsis sp. (Halictidae), Hylaeus sp.(Colletidae) e Polybia sp. (Vespidae) foram consideradas as espécies mais eficientes.

Augochloropsis sp. coletava pólen vibrando os estames, comportamento pouco comum em espécies com anteras de deiscência rimosa. Oliveira \& Sazima (1990) referem-se a outras duas espécies de Clusiaceae (Kielmeyera coriacea e K. speciosa), nas quais o pólen é coletado por vibração. Buchmann (1985) afirma que geralmente as espécies com anteras rimosas polinizadas por vibração apresentam os estames agrupados, como ocorre em V. guianensis.

Hylaeus sp. foi o visitante mais freqüente e um dos mais efetivos. Durante a coleta de pólen entrava em contato várias vezes com as estruturas sexuais da flor, promovendo a polinização.

De maneira geral, vespas visitam apenas flores de néctar (Percival 1965), actinomorfas, pequenas, com corolas formando pequenos tubos (Heithaus 1979) e atuam, em geral, como polinizadores ocasionais, por apresentar poucas adaptações para o transporte de pólen (Proctor et al. 1996). No entanto, Polybia sp. possui pêlos na parte ventral do abdômen, que, em contato com as anteras, ficam cheios de grãos de pólen. Em V. guianensis, Polybia sp. foi um dos polinizadores mais efetivos, devido à esta característica morfológica e à freqüência das visitas às flores.

As abelhas do gênero Trigona coletam pólen e se alimentam de partes florais, como pétalas e estames (Renner 1983). Este comportamento também ocorreu durante as visitas de Trigona sp. às flores de V. guianensis. Plebeia poecilochroa atua como pilhadora de néctar em V. guianensis, podendo reduzir a quantidade de néctar da flor, de modo que os polinizadores precisam visitar maior quantidade de flores, aumentando, indiretamente a possibilidade de polinização cruzada (Camargo et al. 1984).

Considerando que $V$. guianensis é espécie obrigatoriamente xenógama, a diversidade, freqüência e eficiência dos polinizadores são fundamentais para garantir a reprodução sexuada e o estabelecimento desta espécie.

\section{Agradecimentos}

À Ariadna Valentina Lopes, pela ajuda no trabalho de campo e pelas sugestões ao manuscrito; à Luciana Gomes Teixeira, pelas ilustrações e auxílio nos trabalhos de campo 
e de laboratório; ao Pe. José Moure, pela identificação das abelhas; aos dois revisores pelas sugestões ao manuscrito; à COMPESA, por permitir a realização do trabalho na área da Reserva; ao CNPq, pelo apoio financeiro (bolsa PIBIC ao primeiro autor).

\section{Referências bibliográficas}

Adolfo, M. C. dos S. \& Andrade, L. de H. C. 1989. Fenologia de Vismia guianensis (Aublet) \& Choisy (Guttiferae) ocorrente no Jardim Botânico do Curado, Recife, PE. Biologica Brasilica 1(2): 179-193.

Andrade-Lima, D. 1950. Catálogo do Herbário da Escola Agrícola de Tapera (PE). Boletim da Secretaria da Agricultura, Indústria e Comércio 17: 241-319.

Andrade-Lima, D. 1960. Estudos fitogeográficos de Pernambuco. Arquivos do Instituto de Pesquisas Agronômicas 5: 305-341.

Baker, H. G. 1975. Sugar concentrations in nectars from hummingbird flowers. Biotropica 7(1): 37-41.

Barrett, S. C. H. (ed).1992. Evolution and function of heterostyly. Monografs on theoretical and applied genetics 15. Springer-Verlag, Berlin.

Barrett, S. C. H. \& Richards, J. H. 1990. Heterostyly in Tropical Plants. Memoires of the New York Botanical Garden 55: 35-61.

Bittrich, V. \& Amaral, M. C. E. 1997. Floral biology of some Clusia species from Central America. Kew Bulletin 52: 617-635.

Buchmann, S. L. 1985. Bees use vibration to aid pollen colletion from non-poricidal flowers. Journal of the Kansas Entomological Society 58: 517-525.

Camargo, J. M. F; Gottsberger, G. \& Silberbauer-Gottsberger, I. 1984. On the phenology and flowers visiting behavior of Oxaea flavescens (Klug) (Oxalinae, Andrenidae, Hymenoptera) in São Paulo, Brazil. Beiträge zur Biologie der Pfanzen 59: 159-179.

Correia, M. C. R.; Pinheiro, M. C. B., Lima, H. A. 1993. Estudo da biologia floral de Clusia criuva Camb.: um caso de mimetismo. Bradea 24: 209-219.

Cruden, R.W. 1977. Pollen-ovule ratios: a conservative indicator of breeding systems in flowering plants. Evolution 31: 32-46.

Dulberger, R. 1975. Intermorph structural differences between stigmatic papillae and pollen grains in relation to incompatibility in Plumbaginaceae. Proceedings of the Royal Society of London Serie B. 188: 257-274.

Dulberger, R. 1992. Floral polymorphisms and their functional significance in the heterostyly syndrome. Pp. 41-84. In: S. C. H Barrett (Ed.), Evolution and function of Heterostyly. Springer-Verlag, Berlin.

Endress, P.K. 1994. Diversity and evolutionary biology of tropical flowers. Cambridge University Press. Erdtman, G. 1966. Pollen Morphology and Plant Taxonomy. Angiosperm. Hafner. New York.

Faegri, K. \& Van Der Pijl, L. 1979. The principles of pollination ecology. 3. ed. Pergamon Press, London.

Galen, C. \& Plowright, R. C. 1987. Testing the accuracy of using peroxidase activity to indicate stigma receptividade. Canadian Journal of Botany 65: 107-111.

Ganders, F. R. 1979. The biology of heterostyly. New Zeland Journal of Botany 17: 607-635.

Heithaus, E. R. 1979. Flowers visitation records and resource overlap of bees and wasps in northwest Costa Rica. Brenesia 16: 9-52.

Lewis, D. G. 1982. Incompatibility, stamen moviment and pollen economy in a heterostylous tropical forest tree, Cratoxylom formosum (Guttiferae). Proceedings of the Royal Society of London Serie B 214: 273-283.

Lewis, D. G. \& Jones, D. A. 1992. The genetics of heterostyly. Pp. 129-150. In: S. C. H. Barrett (Ed.). Evolution and function of Heterostyly. Springer-Verlag, Berlin.

Lloyd, D. G. 1972. Breeding systems in Cotula L. (Compositae, Anthemideae). I. The array of monoclinous and diclinous systems. New Phytologist 71: 1181-1194.

Lopes, A. V. \& Machado, I. C. 1998. Floral biology and reproductive ecology of Clusia nemorosa (Clusiaceae) in Northeastern Brazil. Plant Systematic and Evolution 213: 71-90.

Mabberley, D. J. 1993. The Plant-Book. Cambridge University Press, New York.

Machado, I. C.; Lopes A. V. \& Pôrto, K. C. (Orgs.). 1998. Reserva ecológica de Dois Irmãos: estudos em um remanescente de Mata Atlântica em área urbana. Secretaria de Ciência, Tecnologia e Meio Ambiente do Estado de Pernambuco. Editora Universitária-UFPE, Recife. 
Maêda, J. M. 1985. Manual para uso da câmara de Neubauer para contagem de pólen em espécies florais. Universidade Federal do Rio de Janeiro, Rio de Janeiro.

Mariz, G. 1974a. Guttiferae of Pernambuco (Brazil). Candollea 29: 7-11.

Mariz, G. 1974b. Two new species of Tovomita Aublet (Guttiferae) from northeastern Brazil. Bulletin of the Torrey Botanical Club 101(6): 367-371.

Mariz, G. 1989. Flora de Pernambuco: Guttiferae I. Revista Biologia Brasilica 1(2): 135-142.

Mariz, G. \& Leal, F. B. 1972. Clusia paralicola, uma nova espécie de Guttiferae de Pernambuco. Revista Brasileira de Biologia 32: 1-43.

Morellato, L. P. C.; Leitão-Filho, H. F.; Rodrigues, R. R. \& Joly, C.A. 1990. Estratégias fenológicas de espécies arbóreas em florestas de altitude na Serra do Japi, Jundiaí, São Paulo. Revista Brasileira de Biologia 50: 149-162.

Newstron, L. E.; Frankie, G. W. \& Baker, H. G. 1994. A new classification for plant phenology based on flowering patterns in lowland tropical rain forest trees at La Selva, Costa Rica. Biotropica 26(2): 141 159.

Oliveira, P. E. A. M. de \& Sazima, M. 1990. Pollination biology of two species of Kielmeyra (Guttiferae) from Brazilian cerrado vegetation. Plant Systatic and Evolution 172: 35-49.

Ornduff, R. 1975. Heterostyly and pollen flow in Hypericum aegypticum (Guttiferae). Botanical Journal of the Linnean Society 71: 51-7.

Ornduff, R. 1979. The genetics of heterostyly in Hipericum aegypticum. Heredity 42: 271-272.

Percival, M. 1965. Floral biology. Pergamon Press, Oxford.

Proctor, M.; Yeo, P. \& Lack, A. 1996. The natural history of Pollination. Harper-Colins Publishers, Oregon.

Radford, A. E.; Dickinson, W. C.; Massey, J. R. \& Bell, C. R. 1974. Vascular plant systematics. Harper \& Row Publishers, New York.

Renner, S. 1983. The widespread occurrence of anther destruction by Trigona bees in Melastomataceae. Biotropica 15: 251-256.

Richards, A. J. 1986. Plant breeding systems. George Allen \& Unwin, London.

Sobrevila, C. \& Arroyo, M. T. K. 1981. Breeding systems in a montane tropical cloud forest in Venezuela. Plant Systematic and Evolution 140: 19-37.

van den Berg, M. E. 1971. Notas sobre Vismia guianensis (Aublet) Chiosy e suas novas variedades. Boletim do Museu Paraense Emílio Goeldi 40: 1-15.

Vuilleumier, B. S. 1967. The origin and evolutionary development of heterostyly in the Angiosperms. Evolution 31: 47-51.

Zar, J. H. 1996. Biostatistical Analysis. Prentice Hall, New York.

Zeisler, M. 1938. Über die Abgrenzung der eigentlichen Narbenflache mit Hilfe von Reaktionen. Beiheft Botanische Zentralblatt 58: 308-318. 